\title{
Comparison between Pure Tone Audiometry and Auditory Steady-State Responses in Korean Children and Adult
}

\author{
Hyong Joo Park, Hong Chan Kim, Dong Joo Shin, and Chul Ho Jang \\ Department of Otolaryngology-Head and Neck Surgery, Chonnam National University Medical School, \\ Chonnam National University Hospital, Gwangju, Korea
}

\author{
국내 소아 및 성인에서의 순음청력검사와 청성안정유발반응의 상관관계 분석 \\ 박형주 · 김홍찬 · 신동주 · 장철호 \\ 전남대학교 의과대학 전남대학교병원 이비인후과학교실
}

\author{
Received June 1, 2014 \\ Revised August 26, 2014 \\ Accepted September 17, 2014 \\ Address for correspondence \\ Chul Ho Jang, MD, PhD \\ Department of Otolaryngology- \\ Head and Neck Surgery, \\ Chonnam National University \\ Medical School, Chonnam National \\ University Hospital, \\ 42 Jebong-ro, Dong-gu, \\ Gwangju 501-757, Korea \\ Tel $+82-62-220-6788$ \\ Fax $+82-62-228-7743$ \\ E-mail chulsavio@hanmail.net
}

\begin{abstract}
Background and Objectives Assessing accurate audiometry might be an important index treating patients with hearing loss. So far there have been no studies on analysis of correlations between pure tone audiometry (PTA) and auditory steady-state response (ASSR) for children in Korea. We analyzed correlations between PTA and ASSR in order to investigate the usefulness of ASSR.

Subjects and Method Past medical records were retrieved from the patients who visited Department of Otolaryngology at Tertiary Referral Hospital from January 2012 to December 2012 and underwent the correlation study between ASSR and PTA with a correlation analysis of frequency. The participants over the age of 15 were classified into the adult group and those below in the children group.

Results There was a statistically significant correlation between the average hearing threshold of ASSR and PTA (correlation coefficient=0.934). There was a strong correlation between children and adult group, too. With the frequency range of 500,1000, 2000, and $4000 \mathrm{~Hz}$, the correlation coefficients were $0.875,0.896,0.915$, and 0.900 , respectively. The degree of hearing loss was classified by using PTA follows: below $25 \mathrm{~dB}$ as normal; between $26-55 \mathrm{~dB}$ as moderate hearing loss; above $56 \mathrm{~dB}$ as severe hearing loss. Correlation coefficients for the above hearing ranges were $0.527,0.670$, and 0.744 , respectively. Strong correlation was found between children and adult group, too.

Conclusion The comparison results between the average hearing threshold of ASSR and PTA indicated that the threshold of ASSR could well reflect the results of both children and adult group. Korean J Otorhinolaryngol-Head Neck Surg 2015;58(3):182-6
\end{abstract}

Key Words Auditory evoked response · Children · Pure tone audiometry.

\section{서 론}

청력검사는 청력 손실의 유무, 난청의 정도 등을 알아볼 수 있는 검사로 환자의 적극적 협조가 요구되는 주관적 검사 법과 협조에 관계없이 측정할 수 있는 객관적 검사법으로 구 분된다. 이 중 검사에 비협조적인 성인이나 협조가 되지 않는
소아 환자의 경우는 기존의 순음청력검사를 통해서는 정확 한 결과를 얻기가 힘들어 다른 대체적인 검사방법이 사용된 다. 대체적 검사방법으로 시각 강화 청력 검사 및 유희 청력 검사 등이 있으나 ${ }^{1)}$ 이 검사들 또한 신뢰도 있는 정보를 얻어 내기 힘들다. 순음청력검사가 불가능할 경우에 다른 객관적 인 검사방법으로 청성뇌간유발반응검사(auditory brainstem 
response)가 있다. ${ }^{2-4)}$ 이 검사는 수면과 마취에 큰 영향을 받 지 않고 미로성 및 후미로성 난청의 감별에도 특이성을 지니 고 있어 널리 쓰이고 있으나 주로 1000 4000 Hz 주파수 범 위의 고음역에 대한 반응으로 저음역에 대한 청력 평가가 어 려울 뿐 아니라 주파수별 와우기능에 대한 정보를 얻을 수 없다는 단점이 있다. ${ }^{5)}$ 또한 한계측정치가 $90 \mathrm{~dB}$ 로 알려져 있 어 $90 \mathrm{~dB}$ 이상의 고도 난청에서 정확한 정보를 얻기 힘들다.

청성뇌간유발반응검사보다 최근에 나온 청성안정유발반 응검사(auditory steady-state response, ASSR)는 지속적인 음 자극에 대한 청각전달로의 지속적인 반응으로 변조음을 자극 음으로 이용하는 청각유발반응이다. ${ }^{6}$ 소리 자극을 주면 내이 의 유모세포가 탈분극하게 되고 이에 의해 청신경섬유가 자극 을 받아 주파수 특이적인 청력 역치를 얻을 수 있으며 $70 \mathrm{~Hz}$ 이상의 높은 변조주파수를 이용할 경우 수면에 영향을 받지 않아 ${ }^{7-9)}$ 영유아나 소아, 혹은 협조가 되지 않는 성인의 객관적 인 청력검사 도구로 이용되고 있다..$^{10-12)}$

또한 청성뇌간유발반응검사의 경우 검사자의 주관적인 판 독에 의하여 반응의 유무가 결정되지만 청성안정유발반응검 사의 경우 자동화된 알고리즘(automatic detection algorithm) 이 반응의 유무를 결정하게 되어 있어 좀 더 객관적이고 신뢰 성 있는 검사가 가능하다. ${ }^{13)}$

이전의 연구에서 청성안정유발반응검사와 순음청력검사의 상관관계는 높은 것으로 보고되어 왔지만 ${ }^{14-17)}$ 소아집단에서 두 검사 간의 연관성을 비교해본 논문은 국내에서는 드문 상 태였다. 이에 저자들은 기존의 순음청력검사만으로는 자세한 청력 정도를 알 수 없는 소아군 및 협조가 되지 않는 성인군 환 자들의 청력검사에 진단적 검사방법으로 널리 쓰이고 있는 청성안정유발반응검사의 유용성을 파악하기 위해 나이, 초기 청력 상태, 주파수에 따른 순음청력검사와 청성안정유발반 응검사와의 상관관계를 분석하였다.

\section{대상 및 방법}

2012년 1월부터 2012년 12월까지 전남대학교병원 이비인후 과에 내원하거나 입원한 환자들 중 순음청력검사와 청성안정 유발반응검사를 동시에 시행받은 환자들을 대상으로 후향적 으로 차트 분석을 시행하였다. 내원 당시의 나이, 초기 청력 상 태, 주파수에 따른 순음청력검사와 청성유발반응검사와의 상 관관계를 분석하였다. 총 142 명(284귀) 중 이경검사상 고막에 이상소견을 보이거나 순음청력검사나 청성안정유발반응검사 에서 반응을 보이지 않는 경우는 제외하였고 총 94명(151귀)이 본 연구에 참여되었다.

또한 15 세를 기준으로 소아군과 성인군으로 나누어 각 군
별로 순음청력검사와 청성안정유발반응검사와의 상관관계 를 분석하였다. 15 세 미만의 소아군은 16 명(26귀)이었으며 4 14세까지 분포하였고 평균 나이는 8세였다. 15세 이상의 성 인군은 78명(125귀)이었고 16 83세까지 분포하였으며 평균 나 이는 47세였다.

모든 피검자들의 순음청력검사를 확인 후 청성안정유발검 사를 시행하였다. 피검자는 최대한 안정을 취한 상태로 침대에 누운 채 검사를 시행하였으며 소아의 경우 chloral hydrate를 체중에 따라 먹여 수면 유도 후 검사를 시행하였다. 양측 귀의 검사 소요시간은 40 50분이었으며 청력 역치를 구할 수 없는 결과는 제외하였다. 평균 청력 역치는 6분법을 이용하여 계산 하였으며 순음청력검사와 청성안정유발반응검사를 시행한 환 자들 중 청력 역치를 구할 수 없는 경우는 분석에서 제외하였 다. 청성안정유발반응검사의 경우 Biologic사의 MASTER system을 이용하여 측정하였고 방음실에서 피검자가 편안히 누 운상태에서 검사를 진행하였다. 전극은 앞이마, 목뒤부분, 어 깨에 부착하였고 80 99 Hz의 변조주파수를 이용하여 500, $1000,2000,4000 \mathrm{~Hz}$ 의 주파수에서 양쪽 귀의 청력 역치를 측정하였다. 소아와 성인군 각 군마다 두 군 사이의 순음청력 검사와 청성안정유발반응검사의 상관관계를 분석하였고 청 력 소실 정도에 따라 세 군으로 나누어 각 군별로 순음청력검 사와 청성안정유발반응검사의 상관관계를 분석하였다.

통계학적 분석은 SPSS(version 19.0; SPSS Inc., Chicago, $\mathrm{IL}, \mathrm{USA}$ ) bivariate correlation analysis를 이용하였고 $p$ 값이 0.05 이하일 시 통계학적으로 유의한 것으로 해석하였다.

\section{결 과}

\section{전체군에서의 순음청력검사와 청성안정유발반응검사의 평균 청력역치의 비교}

소아군과 성인군(151귀)을 대상으로 6 분법으로 구한 평균 순음청력역치 검사와 청성안정유발반응검사의 상관계수는 0.934 로 청성안정유발반응검사의 평균 청력역치가 순음청력 검사의 결과를 잘 반영하는 것으로 나타났다 $(p<0.05)$. 순음 청력검사와 청성안정유발반응검사와의 상관관계방정식은 pure tone audiometry $(\mathrm{PTA})=0.993 \times \mathrm{ASSR}-11.79$ 로 정의되 었다(Fig. 1).

\section{소아군에서의 순음청력검사와 청성안정유발반응검사의 평균 청력역치의 비교}

소아군(26귀)을 대상으로 6분법으로 구한 평균 순음청력 역치 검사와 청성안정유발반응검사의 상관계수는 0.982 로 청 성안정유발반응검사의 평균 청력역치가 순음청력검사의 결과 


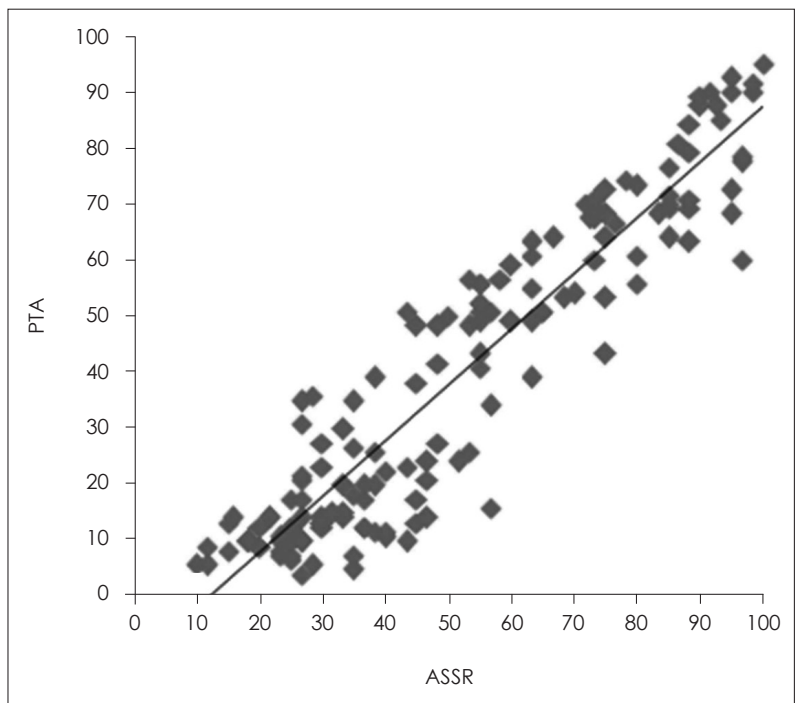

Fig. 1. Bivariate correlation analysis of the relation between PTA and ASSR thresholds (all groups). The correlation coefficient $(r)$ is $0.934(p<0.05)$. PTA=0.993 $\times$ ASSR-11.79. PTA: pure tone audiometry, ASSR: auditory steady-state response.

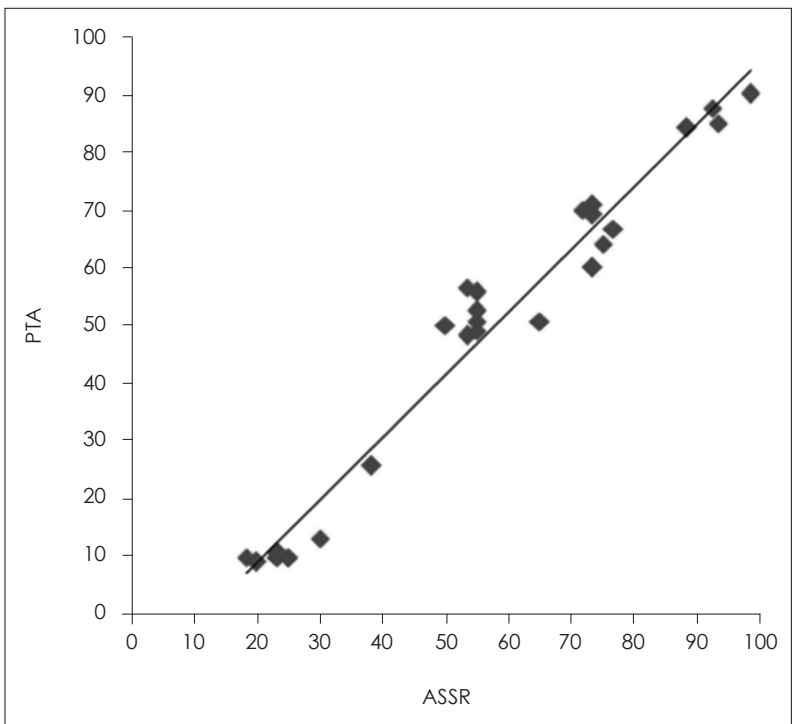

Fig. 2. Bivariate correlation analysis of the relation between PTA and ASSR thresholds (children groups). The correlation coefficient $(r)$ is $0.982(p<0.05)$. PTA=1.083 $\times$ ASSR-12.40. PTA: pure tone audiometry, ASSR: auditory steady-state response.

를 잘 반영하는 것으로 나타났다 $(p<0.05)$. 순음청력검사와 청성안정유발반응검사와의 상관관계방정식은 $\mathrm{PTA}=1.083 \times$ ASSR-12.40으로 정의되었다(Fig. 2, Table 1).

\section{성인군에서의 순음청력검사와 청성안정유발반응검사의 평균 청력역치의 비교}

성인군(125귀)을 대상으로 6분법으로 구한 평균 순음청력 역치 검사와 청성안정유발반응검사의 상관계수는 0.926 으로 청성안정유발반응검사의 평균 청력역치가 순음청력검사의
Table 1. PTA and ASSR values (children group)

\begin{tabular}{|c|c|c|c|c|c|}
\hline & Age (yr) & Gender & PTA (dB) & ASSR (dB) & $A B G(d B)$ \\
\hline Children 1 & 14 & Female & 9 & 20 & 10 \\
\hline Children 2 & 6 & Male & 10 & 18 & 10 \\
\hline Children 3 & 7 & Female & 10 & 23 & 5 \\
\hline Children 4 & 9 & Male & 10 & 25 & 5 \\
\hline Children 5 & 13 & Male & 10 & 25 & 10 \\
\hline Children 6 & 7 & Male & 11 & 23 & 5 \\
\hline Children 7 & 7 & Male & 13 & 30 & 5 \\
\hline Children 8 & 10 & Male & 26 & 38 & 10 \\
\hline Children 9 & 5 & Male & 48 & 53 & 15 \\
\hline Children 10 & 8 & Female & 49 & 55 & 10 \\
\hline Children 11 & 7 & Male & 50 & 50 & 15 \\
\hline Children 12 & 6 & Female & 51 & 55 & 5 \\
\hline Children 13 & 8 & Female & 51 & 65 & 25 \\
\hline Children 14 & 8 & Female & 53 & 55 & 10 \\
\hline Children 15 & 6 & Female & 56 & 55 & 10 \\
\hline Children 16 & 5 & Female & 57 & 53 & 20 \\
\hline Children 17 & 8 & Female & 60 & 73 & 25 \\
\hline Children 18 & 7 & Female & 64 & 75 & 10 \\
\hline Children 19 & 7 & Female & 67 & 77 & 10 \\
\hline Children 20 & 4 & Male & 69 & 73 & 10 \\
\hline Children 21 & 10 & Female & 70 & 72 & 30 \\
\hline Children 22 & 4 & Male & 71 & 73 & 10 \\
\hline Children 23 & 7 & Male & 84 & 88 & 15 \\
\hline Children 24 & 9 & Male & 85 & 93 & 15 \\
\hline Children 25 & 13 & Female & 88 & 93 & 10 \\
\hline Children 26 & 7 & Male & 90 & 98 & 15 \\
\hline
\end{tabular}

Mean PTA, ASSR $=(500 \mathrm{~Hz}+2 \times 1000 \mathrm{~Hz}+2 \times 2000 \mathrm{~Hz}+4000 \mathrm{~Hz}) / 6$. $\mathrm{dB}$ : decibel, PTA: pure tone audiometry, ASSR: auditory steadystate response, $A B G$ : air-bone gap

결과를 잘 반영하는 것으로 나타났다 $(p<0.05)$. 순음청력검사 와 청성안정유발반응검사와의 상관관계방정식은 $\mathrm{PTA}=0.968 \times$ ASSR-11.46으로 정의되었다(Fig. 3).

\section{순음청력검사와 청성안정유발반응검사의 주파수별 청력역치의 비교}

순음청력검사와 청성안정유발반응검사의 청력역치를 각각 $500,1000,2000,4000 \mathrm{~Hz}$ 의 주파수별 상관관계를 분석한 결과 상관계수는 각각 $0.875,0.896,0.915,0.900$ 으로 전반적 으로 비교적 높은 상관계수를 보였다 $(p<0.05) .2000 \mathrm{~Hz}$ 에서 가장 높은 상관계수를 보였고 각 주파수별로 산출된 두 검사 간의 상관관계방정식은 $\mathrm{PTA}=0.966 \times \mathrm{ASSR}-11.26, \mathrm{PTA}=0.971 \times$ ASSR-10.72, PTA=0.987 $\times$ ASSR-11.57, PTA=0.978 $\times$ ASSR10.16 으로 정의되었다. 또한 각 주파수별로 순음청력 검사와 청성안정유발반응검사의 평균역치값 차이는 각각 500,1000 , $2000,4000 \mathrm{~Hz}$ 별로 13.0, 12.2, 12.2, $11.3 \mathrm{~dB}$ 을 보이고 있었 다(Table 2). 소아군에서 주파수별 상관관계를 분석한 결과 상 


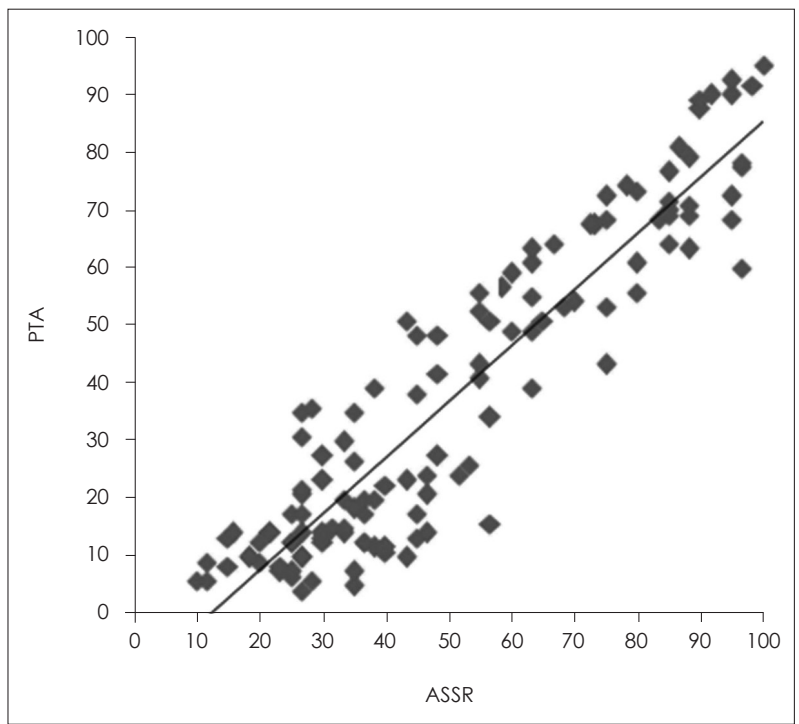

Fig. 3. Bivariate correlation analysis of the relation between PTA and ASSR thresholds (adult groups). The correlation coefficient ( $r$ ) is $0.926(p<0.05)$. PTA=0.968 $\times$ ASSR-11.46. PTA: pure tone audiometry, ASSR: auditory steady-state response.

Table 2. Mean PTA and ASSR values according to frequencies

\begin{tabular}{lcccc}
\hline \multicolumn{1}{c}{ Category } & $500 \mathrm{~Hz}$ & $1000 \mathrm{~Hz}$ & $2000 \mathrm{~Hz}$ & $4000 \mathrm{~Hz}$ \\
\hline Mean PTA $(\mathrm{dB})$ & 40.2 & 40.4 & 38.5 & 40.1 \\
Mean ASSR $(\mathrm{dB})$ & 53.2 & 52.6 & 50.7 & 51.4 \\
Difference $(\mathrm{dB})$ & 13.0 & 12.2 & 12.2 & 11.3 \\
\hline
\end{tabular}

Mean PTA, ASSR $=(500 \mathrm{~Hz}+2 \times 1000 \mathrm{~Hz}+2 \times 2000 \mathrm{~Hz}+4000 \mathrm{~Hz}) / 6 . \mathrm{dB}$ : decibel, PTA: pure tone audiometry, ASSR: auditory steady-state response

관계수는 각각 $0.906,0.970,0.945,0.919$ 로 전반적으로 비교 적 높은 상관계수를 보였고 성인군에서 주파수별 상관관계 를 분석한 결과 상관계수는 각각 $0.866,0.883,0.913,0.897$ 로 전반적으로 비교적 높은 상관계수를 보이고 있었다.

\section{순음청력검사와 청성안정유발반응검사의 난청의 정도별 청력역치의 비교}

순음청력검사의 결과를 기준으로 평균 청력이 $25 \mathrm{~dB}$ 이하 를 정상청력, 26 55 dB을 중등도 난청, $56 \mathrm{~dB}$ 이상을 고도 난청의 세 그룹으로 분류하였고 각각 상관계수는 0.527 , $0.670,0.744$ 의 값을 보여 고도 난청으로 갈수록 상관계수가 증가하는 추세를 보였다. 소아군에서의 난청정도별 청력역치 를 비교해 보았을 때 각각 상관계수는 $0.791,0.832,0.940$ 의 값을 보였고 성인군에서의 난청정도별 청력역치를 비교해 보 았을 때 각각 상관계수는 $0.505,0.665,0.683$ 의 값을 보여 각 군별로 분석해 보았을 때에도 고도 난청으로 갈수록 상관계 수가 증가하는 추세를 보이고 있었다(Fig. 4).

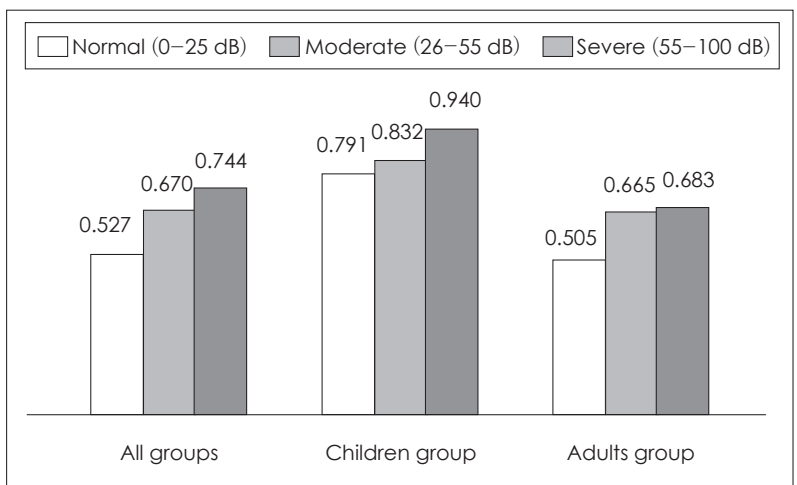

Fig. 4. Correlation coefficient for pure tone audiometry andauditory steady-state response hearing threshold level with respect to the level of hearing loss $(0-25 \mathrm{~dB}$ as normal, $26-55 \mathrm{~dB}$ as moderate, $56-100 \mathrm{~dB}$ as severe hearing loss).

\section{고 찰}

청성안정유발반응검사는 지속적인 음자극에 대한 청각전 달로의 지속적인 반응으로 진폭 혹은 주파수가 주기적으로 변조된 순음을 자극음으로 이용하는 청각유발반응이다. 청성 안정유발반응검사는 주파수의 특이적인 청력역치를 제공하 고 $70 \mathrm{~Hz}$ 이상의 높은 변조주파수를 이용할 경우 수면에 영향 을 받지 않으며 자동화된 역치측정 방식으로 비숙련자도 검 사하기 용이하다는 장점이 있어 영유아의 객관적인 청력검사 도구로 이용되고 있다. 여러 연구에서도 두 검사 간의 상관관 계를 연구한 결과가 발표되었는데 Lee 등네)에 의하면 순음청 력검사와 창성안정유발반응검사의 상관계수는 0.960 으로 매우 높은 상관관계를 보였으며 Dimitrijevic 등히에 의하면 0.920 으로 역시 매우 높은 상관관계를 보여주었다.

본 연구에서 순음청력검사와 창성안정유발반응검사의 6분 법으로 구한 전체 환자군 평균 청력역치의 상관계수는 0.934 로 이전의 연구결과와 동일하게 매우 높은 것을 알 수 있었다. 순음청력검사 결과를 기준으로 정상청력, 중등도 난청, 고도 난청군으로 분류한 경우에 정상청력에서는 0.527 , 중등도 난 청에서는 0.670 , 고도 난청에서는 0.744 의 상관계수를 보이고 있어 고도 난청을 지닌 사람일수록 순음청력검사와 청성안정 유발반응검사와의 연관성이 높은 것으로 알 수 있었다.

1995년 Rance 등 ${ }^{18}$ 이 발표한 논문에 따르면 정상청력군에 서 고도 난청군으로 진행할수록 청성안정유발반응검사의 청 력역치와 순음청력검사와의 역치의 차이가 줄어드는 결과가 도출되었으며 본 연구결과에서도 정상청력군에서 고도 난청 군으로 진행할수록 역치의 차이가 줄어들면서 상관계수가 $0.527,0.670,0.744$ 로 증가하는 결과를 보여주었다. 또한 소 아와 성인군으로 나누어서 분석을 해보았을 때에도 동일한 결과를 얻을 수 있었다. 이는 감각신경성난청 환자들에게서 
일반적으로 발생하는 누가현상(recruitment)과 관련이 있다. ${ }^{18)}$ 정상 환자군에서는 상관계수가 0.527 로 고도 난청 환자군에 서의 상관계수 0.744 에 비해 낮은 값을 보여주고 있으며 이는 정상 환자군에서 청성안정유발반응검사의 유용성이 고도 난 청 환자군에서보다 다소 떨어지는 것으로 알 수 있었다.

소아군에서의 청성안정유발반응검사의 유용성을 알아보 기 위하여 순음청력검사와 청성안정유발반응검사의 6분법 으로 구한 평균 청력역치의 상관계수를 소아 환자군과 성인 환자군으로 비교를 시행하였으며 상관계수는 각각 0.982 , 0.926으로 소아군에서 더 높게 나왔고 두 군 모두에서 강한 상관관계가 있는 것으로 나타났다.

주파수별 순음청력검사와 청성안정유발반응검사의 6분법 으로 구한 평균 청력역치의 상관계수는 $500,1000,2000,4000$ $\mathrm{Hz}$ 에서 각각 $0.875,0.896,0.915,0.900$ 으로 전반적으로 비교 적 높은 상관계수를 보였다. $4000 \mathrm{~Hz}$ 에서 약간 감소하였지 만 주파수가 커질수록 상관계수는 증가하는 양상을 보이고 있었다.

소아군에서의 순음청력검사와 청성안정유발반응검사와의 상관계수는 0.982로 매우 높은 상관관계임을 알 수 있었고 이 는 청성안정유발반응검사가 성인군에서뿐만 아니라 순음청 력검사 시행이 어려운 소아 환자군에서의 청력평가에 매우 중 요한 역할을 해줄 수 있는 검사방법임을 알 수 있었다. 특히 소 아 난청의 경우 출생 후 빠른 시간 안에 청각재활 및 청능훈련 이 이루어져야 언어 및 정서 발달의 호전을 기대할 수 있어 ${ }^{19,20)}$ 청성안정유발반응검사의 중요성이 커지고 있으며 최근에 들 어와서는 신생아청력검사에서도 청성안정유발반응검사가 유 용하게 쓰이기 시작하였다. ${ }^{21)}$ 이는 본 연구에서 유아의 경우 순음청력검사가 불가능하기 때문에 시행하지 못하였지만 유 아에서도 유용하게 청력역치를 측정하는 데 쓰일 수 있음을 알 수 있었고 이에 따라 앞으로 더욱 활용분야가 넓어질 것으 로 예상된다.

\section{REFERENCES}

1) Thakore H, McMahon T. Designing an interactive multimedia rich tutorial for medical students: beyond a 'book on a screen'. J Vis Commun Med 2008;31(1):4-10.

2) Stevens J, Boul A, Lear S, Parker G, Ashall-kelly K, Gratton D. Predictive value of hearing assessment by the auditory brainstem response following universal newborn hearing screening. Int $\mathbf{J}$ Audiol 2013;52(7):500-6.

3) Seo JH, Jeon EJ, Park YS, Kim JE, Kim DH, Nam IC, et al. Correlation of threshold of click-evoked auditory brainstem response with pure- tone threshold average in various formulas. Korean J OtorhinolaryngolHead Neck Surg 2012;55(12):764-70.

4) van der Drift JF, Brocaar MP, van Zanten GA. The relation between the pure-tone audiogram and the click auditory brainstem response threshold in cochlear hearing loss. Audiology 1987;26(1):1-10.

5) Gorga MP, Worthington DW, Reiland JK, Beauchaine KA, Goldgar DE. Some comparisons between auditory brain stem response thresholds, latencies, and the pure-tone audiogram. Ear Hear 1985;6(2):105-12.

6) Lee SH. Auditory steady state evoked responses (ASSR). Korean J Otolaryngol 2003;46(8):621-6.

7) Cone-Wesson B, Rickards F, Poulis C, Parker J, Tan L, Pollard J. The auditory steady-state response: clinical observations and applications in infants and children. J Am Acad Audiol 2002;13(5):270-82.

8) Laukli E, Fjermedal O, Mair IW. Low-frequency auditory brainstem response threshold. Scand Audiol 1988;17(3):171-8.

9) Jerger J, Chmiel R, Frost JD Jr, Coker N. Effect of sleep on the auditory steady state evoked potential. Ear Hear 1986;7(4):240-5.

10) Attias J, Buller N, Rubel Y, Raveh E. Multiple auditory steady-state responses in children and adults with normal hearing, sensorineural hearing loss, or auditory neuropathy. Ann Otol Rhinol Laryngol 2006; 115(4):268-76.

11) Picton TW, Skinner CR, Champagne SC, Kellett AJ, Maiste AC. Potentials evoked by the sinusoidal modulation of the amplitude or frequency of a tone. J Acoust Soc Am 1987;82(1):165-78.

12) Rickards FW, Tan LE, Cohen LT, Wilson OJ, Drew JH, Clark GM. Auditory steady-state evoked potential in newborns. Br J Audiol 1994;28(6):327-37.

13) Kuwada S, Batra R, Maher VL. Scalp potentials of normal and hearingimpaired subjects in response to sinusoidally amplitude-modulated tones. Hear Res 1986;21(2):179-92.

14) Lee HS, Ahn JH, Kim YJ, Lee KS, Yoon TH, Chung JW. The correlation between pure tone audiometry and auditory steady state response according to the hearing level and frequency. Korean J OtolaryngolHead Neck Surg 2006;49(6):593-7.

15) Scherf F, Brokx J, Wuyts FL, Van de Heyning PH. The ASSR: clinical application in normal-hearing and hearing-impaired infants and adults, comparison with the click-evoked ABR and pure-tone audiometry. Int J Audiol 2006;45(5):281-6.

16) Dimitrijevic A, John MS, Van Roon P, Purcell DW, Adamonis J, Ostroff $\mathrm{J}$, et al. Estimating the audiogram using multiple auditory steady-state responses. J Am Acad Audiol 2002;13(4):205-24.

17) Cho SJ, Lee JH, Kim JS, Kim HJ. A comparison of auditory steadystate response thresholds to pure tone thresholds in persons with normal hearing and sensorineural hearing loss. Korean J Audiol 2003; 7(1):57-62.

18) Rance G, Rickards FW, Cohen LT, De Vidi S, Clark GM. The automated prediction of hearing thresholds in sleeping subjects using auditory steady-state evoked potentials. Ear Hear 1995;16(5):499-507.

19) Ruben RJ. Early identification of hearing impairment in infants and young children. Int J Pediatr Otorhinolaryngol 1993;27(3):207-13.

20) Kasai N, Fukushima K, Omori K, Sugaya A, Ojima T. Effects of early identification and intervention on language development in Japanese children with prelingual severe to profound hearing impairment. Ann Otol Rhinol Laryngol Suppl 2012;202:16-20.

21) Jakubíková J, Kabátová Z, Pavlovcinová G, Profant M. Newborn hearing screening and strategy for early detection of hearing loss in infants. Int J Pediatr Otorhinolaryngol 2009;73(4):607-12. 